\title{
Longitudinal Psychological Assessment in Tetralogy of Fallot
}

Eric Lon Shampaine, Lorraine Nadelman, Amnon Rosenthal, Douglas Behrendt, and Herbert Sloan

Division of Pediatric Cardiology, Department of Psychology, and the Section of Thoracic Surgery, University of Michigan Medical School, Ann Arbor, Michigan. USA

SUMMARY. To determine whether preoperative psychological testing in children with cyanotic heart disease could provide an accurate estimate of adult performance, we studied 21 subjects (mean age, $30.3 \pm 4.8$ years) who had undergone surgical repair for tetralogy of Fallot between 1958 and 1966 (mean age, $8.7 \pm 3.9$ years); 17 received childhood preoperative testing (mean age, $8.9 \pm 4.2$ ) and four had early postoperative testing. Follow-up psychological tests administered in 1983 included Wechsler Adult Intelligence Scale Revised, Jackson Personality Research Form E, Rosenberg Self-Esteem Scale, and a questionnaire-interview on educational, occupational, and psychosocial status. Adult IQ $(x=93.4 \pm 15.6)$ and child $1 Q(x=97.5 \pm$ 14.6) scores were highly correlated $(r=0.87, p<0.01)$, revealing considerable stability across $22.3 \pm 2.2$ years. On 17 of 22 Jackson personality scales, the subjects (S) were within the normal range. Scoring below the 16th percentile were 11/21 S on intellectual curiosity, 9/21 S on adaptability to change, and $8 / 21 \mathrm{~S}$ on leadership skills. Scoring above the 84 th percentile were 8/21 $\mathrm{S}$ on harm avoidance and $8 / 21 \mathrm{~S}$ on giving nurturance to others. Univariate one-way ANOVAs indicated that those subjects with the higher IQ scores had the higher incomes, job levels, and educational attainments. We conclude that the results of perioperative psychological testing in children with tetralogy of Fallot are congruent with postoperative adult intellectual and psychosocial status.

KEY WORDS: Congenital heart disease - Intelligence testing - Psychological testing Tetralogy of Fallot - Follow-up

In the four decades since the creation of the Blalock-Taussig anastomosis [1], advances in diagnostic and surgical skills in managing tetralogy of Fallot (TOF) have led to a cumulative survival rate of $94.4 \%$ at 25 years postoperatively [17]. Most parents of the $\sim 2700$ babies born with TOF annually in the United States [4] can now take comfort in an excellent medical prognosis for their child.

Surgical success, however, is not a sufficient harbinger of psychological well-being. Children with congenital heart disease experience disorders of anxiety, neuroses, and diminished self-esteem at a frequency $2-3$ times greater than the physically normal population [10]. Additionally, some studies have found that children with cyanotic heart disease

Address reprint requests 10: Dr. Amnon Rosenthal, Division of Pediatric Cardiology, C.S. Mott Children's Hospital, Box 66, Ann Arbor, MI 48109-0204, USA. have cognitive deficits. Silbert et al. [18] reported that children aged $4-8$ years with cyanotic heart disease had lower IQ scores, poorer gross motor coordination, and poorer performance on perceptual motor tasks than children of equivalent ages with noncyanotic heart disease and a benign medical history. Linde et al. [9] noted that both cyanotic and acyanotic children aged 6 months to 6 years with congenital heart disease scored lower than normals on developmental and intelligence tests. Since the first group of patients to undergo surgical repair of TOF has already reached middle age, the question is whether the psychological impairments identified by childhood testing persist into adult life.

To answer the question, we conducted a longitudinal study to determine whether preoperative psychological testing ir children with TOF could provide an accurate estimate of adult performance. The study was designed to test the hypothesis that 
Table 1. Descriptive age data for surgical repair and psychological testing for the entire group $(n=21)$ and for those with preoperative testing $(n=17)$

\begin{tabular}{llll}
\hline & $n$ & $\begin{array}{l}\text { Mean } \pm \mathrm{SD}^{\mathrm{a}} \\
\text { (years) }\end{array}$ & $\begin{array}{l}\text { Range } \\
\text { (years) }\end{array}$ \\
\hline $\begin{array}{l}\text { Age at surgical repair } \\
\quad \text { Entire group }\end{array}$ & 21 & $8.7 \pm 3.9$ & $3.0-17.0$ \\
$\begin{array}{l}\text { Preop testing group } \\
\text { Age at childhood testing }\end{array}$ & 17 & $9.6 \pm 3.7$ & $3.0-17.0$ \\
$\begin{array}{l}\text { Preop testing group } \\
\text { Age at adult testing } \\
\quad \text { Entire group } \\
\text { Preop testing group }\end{array}$ & 17 & $8.9 \pm 4.2$ & $2.0-16.0$ \\
\hline
\end{tabular}

a $S D$, standard deviation.

preoperative intelligence and personality measures would tend to underestimate the psychosocial and cognitive functioning in adults with repaired TOF. Our hypothesis was based on the assumption that surgical correction of the cardiac lesion and elimination of the cyanosis should lead to an improvement in physical, psychological, and cognitive performance on follow-up testing some 22 years postoperatively.

\section{Materials and Methods}

\section{Subjects}

We reviewed the hospital records of 162 survivors of surgical repair for TOF performed prior to 1967 at the University of Michigan Hospital [17]. From the group, we identified 28 adults ( $17.3 \%$ ) who had received perioperative psychological testing in childhood, including several of the following measures: Cattell Infant Intelligence Scale, Stanford-Binet Forms $L$ and $M$, Wechsler Intelligence Scale for Children, Goodenough Draw-APerson, and psychological interviews. These adults had undergone complete medical examination and noninvasive cardiovascular tests between December 1981 and June 1983.

Each of the 28 individuals was contacted by letter and telephone to obtain consent for follow-up psychological testing to be administered by a medical student who was blind to the results of the childhood testing; $22(78.6 \%)$ agreed to schedule a 3 -h appointment during the summer of 1983 . Four refused to participate and two could not be reached. One subject was excluded from further analysis because on testing, both perioperatively and 14 years postoperatively, he was too mentally retarded to respond to any of the psychological measures other than intelligence testing.

Complete data were obtained from 21 subjects (mean age, $30.3 \pm 4.8$ years) who had undergone surgical repair for TOF between 1958 and 1966. There were 11 male subjects and 10 female subjects. Of the 21 subjects, $15(71.4 \%)$ had one or more palliative procedures performed prior to the surgical repair for TOF. Perioperatively, some of the children had participated in multiple batteries of psychological testing while others had participated in only a single administration. Therefore, our study was limited to the childhood data closest to, and usually immediately preceding, the surgical repair.
In total, 17 of the 21 subjects (nine men and eight women) had preoperative testing in childhood and four (two men and two women) had only early postoperative testing. Table 1 lists the ages at surgical repair, at childhood psychological testing, and at follow-up adult testing for the entire group of 21 subjects and the subset of 17 subjects with preoperative testing.

Prior to childhood cardiac repair, all 21 subjects were cyanotic: 11 exhibited mild cyanosis (mean arterial oxygen saturation, $86.8 \pm 5.0 \%$ ), nine exhibited moderate cyanosis (mean saturation, $78.4 \pm 6.9 \%$ ), and one exhibited severe cyanosis (oxygen saturation, $65 \%$ ). After repair, none of the subjects was cyanotic.

Postoperative adult clinical status was assessed by the New York Heart Association Functional Classification [2] prior to adult psychological testing. Fourteen subjects $(66.7 \%)$ were found to be in class I (no limitation on physical activity), five $(23.8 \%)$ were in class II (slight limitation on physical activity), and (wo $(9.5 \%)$ were in class III (marked limitation on physical activity). No subjects were in class IV (inability to carry on any physical activity without discomfort).

\section{Measures}

The follow-up appointment was usually held in the subject's home. After rapport was established, the senior author, then a medical student (trained and supervised by the second author, a psychologist) administered four psychological tests in the following order: the Wechsler Adult Intelligence Scale Revised (WAISR) [20], the Jackson Personality Research Form E (PRF-E) [7], the Rosenberg Self-Esteem Scale [16], and a questionnaire-interview assessing the subject's educational and psychosocial stalus.

Each of the four tests elicited a different aspect of the subject's psychological and intellectual functioning. The widely used WAIS-R contained six verbal and five nonverbal tests that provided three separate measures of intelligence: a verbal, performance, and full-scale IQ. The 352-itcm Jackson PRF-E was utilized because its 22 personality scales are focused principally upon areas of normal functioning instead of psychopathology. The ten questions on the Rosenberg scale were used to ascertain each subject's self-esteem. To close the follow-up appointment, a questionnaire-interview designed by Shampaine and Nadelman provided information on the educational, occupational, and income levels of the subjects and their parents and siblings. This information allowed for comparisons between the socioeconomic status of the subjects and their parents and siblings. During the interview, the subjects also described their recreational activities, social and family lives, and overall satisfaction with their accomplishments.

\section{Statistical Methods}

Statistical methods used included paired and unpaired $t$-tests, linear correlation, analysis of variance, and chi-square goodnessof-fit technique.

\section{Results}

\section{Intelligence}

Table 2 summarizes the average adult and child IQs for the entire group of 21 subjects and for the subset 
Table 2. Summary of IQ test scores for the entire group $(n=21)$ and for those with preoperative testing $(n=17)$

\begin{tabular}{lccc} 
& $n$ & Mean $\pm \mathrm{SD}^{\mathrm{a}}$ & \\
\hline $\begin{array}{l}\text { Wechsler Verbal Adult IQ } \\
\quad \text { Entire group }\end{array}$ & 21 & $91.0 \pm 17.5$ & $53.0-121.0$ \\
Wechsler Performance Adult IQ & & & \\
$\quad$ Entire group & 21 & $93.6 \pm 15.4$ & $62.0-136.0$ \\
Wechsler Full-Scale Adult IQ & & $91.1 \pm 17.1$ & $56.0-129.0$ \\
$\quad$ Entire group & 21 & $93.4 \pm 15.6$ & $69.0-129.0$ \\
$\quad$ Preop testing group & 17 & $97.5 \pm 14.6$ & $75.0-122.0$ \\
$\quad$ Child IQ & 17 & &
\end{tabular}

"SD, standard deviation

${ }^{\text {b }}$ Child IQ tests administered included Cattell Infant Intelligence Scale. Stanford-Binet Forms L and M. and Wechsler Intelligence Scale for Children.

of 17 subjects with preoperative testing. As shown in Table 2 , the 17 subjects with preoperative testing had a mean IQ in childhood of $97.5 \pm 14.6$ (range, $75.0-122.0$ ) and mean full-scale IQ in adulthood of $93.4 \pm 15.6$ (range, 69.0-129.0).

As expected, there was a direct relationship between the child IQ scores and the adult IQ full-scale $(r=0.87, p<0.01)$, verbal $(r=0.86, p<0.01)$, and performance scores $(r=0.78, p<0.01)$. Although there was a statistically significant difference on a paired $t$-test between the full-scale adult and child IQ scores $(p<0.04)$, this was not considered a meaningful difference because different tests are used to measure child and adult IQs, both child and adult mean IQ scores fell within the average IQ classification, and the difference between them fell within an expected test-retest error of five points.

Therefore, we conclude from the above data that child and adult IQ scores remained relatively stable over a period of $22.3 \pm 2.2$ years.

\section{Personality}

During childhood, $16(76.2 \%)$ of the 21 subjects were assessed frequently and regularly by a clinical psychologist, and five $(23.8 \%)$ were assessed only once. The psychologist interviewed them and administered child intelligence and Goodenough Draw-A-Person tests. Considering only the examination closest to, and usually preceding, the surgical repair for TOF, we noted the following characteristics from their clinical records. Seven subjects (33.3\%) exhibited lags in intellectual development generally involving vocabulary, abstract reasoning, or conceptual skills. The children were understandably anxious about the operation, and 12 (57.1\%) showed signs of depression, passivity, or dependency. The figure drawings of seven children $(33.3 \%)$ were immature, and six children $(28.6 \%)$ displayed some problems with sexual identification and differentiation. Through the drawings and interviews, three children (14.3\%) expressed their concerns about bodily intactness, injury, and death. Six $(28.6 \%)$ were worried often about their adequacy in school, achievement, and interpersonal relations. Feelings of being different from other children troubled four $(19.0 \%)$. Three $(14.3 \%)$ were distracted and had short attention spans. Four (19.0\%) showed signs of rigidity and constriction, three (14.3\%) had notably low energy levels, and three $(14.3 \%)$ displayed immature behavior or speech. Two children (9.5\%) used their illness to manipulate adults.

In adulthood, the entire group of 21 subjects scored within the normal range on 17 of 22 Jackson personality scales, including affiliation, aggression, exhibition, impulsivity, play, and succorance. However, significantly divergent scores were attained on five scales. Scoring below the 16 th percentile of norms (i.e., more than one standard deviation below the mean) for the PRF-E were 11 $(52.4 \%)$ of the 21 subjects on intellectual curiosity (Jackson scale title: Understanding), nine subjects (42.9\%) on adaptability to change (Change), and eight subjects $(38.1 \%)$ on leadership skills (Dominance). Scoring above the 84th percentile of norms (i.e., more than one standard deviation above the mean) for the PRF-E were eight subjects $(38.1 \%$ ) on avoiding risk of bodily harm (Harm Avoidance) and eight subjects $(38.1 \%)$ on giving nurturance to others (Nurturance).

The childhood personality descriptions of our subjects, based on figure drawings and interviews, are not related easily to the Jackson scales on an individual level. Nevertheless, some concordances can be seen. For example, a child for whom future passivity was predicted did score high as an adult in abasement and need for succorance and low in autonomy. A subject who feared injury in childhood scored high in harm avoidance as an adult, while 
another subject who was a dependent child scored low in autonomy as an adult. By and large, however, such direct relationships are difficult to discern from these data.

An unexpected finding in adulthood was the inverse relationship between the Jackson scale on harm avoidance and the subjects' overall clinical status as measured by the New York Heart Association Functional Classification $(r=-0.43, p<$ 0.05 ). Thus, the greater the degree of harm avoidance that the subjects showed on their PRF-E responses, the less physically impaired they were clinically.

Relating the Jackson personality scales to the adult full-scale IQ scores demonstrated significant direct relationships between the IQ scores and adaptability to change $(r=0.56, p<0.01)$, intellectual curiosity $(r=0.58, p<0.01)$, aesthetic appreciation (Jackson scale title: Sentience, $r=0.74, p<$ 0.01 ), and approval seeking (Social Recognition, $r$ $=0.43, p<0.05$ ). Thus, the higher the full-scale IQ score, the greater the degree to which each of these four personality characteristics was reported. Additionally, two inverse relationships were demonstrated between the adult IQ scores and the Jackson scales on harm avoidance $(r=-0.49, p<0.05)$ and infrequency (Infrequency, which means responding in a random manner to the PRF-E questionnaire; $r=-0.56, p<0.01$ ).

Sex differences were exhibited on three of the Jackson personality scales, though most of the subjects' scores on these three scales were within the normal range. Two-sample $t$-tests disclosed that men scored significantly higher than did women on need for succorance (Jackson scale title: Succorance, $p<0.05$ ) and favorable orientation toward play (Play, $p<0.04$ ). There was a trend for women to score higher on autonomy than did men (Autonomy, $p<0.07$ ).

\section{Self-Esteem}

On the Rosenberg scale, 17 subjects $(81.0 \%)$ reported high self-esteem by scoring 26 or more on a 10 to 40 -point scale. Two subjects $(9.5 \%)$ showed marginal self-esteem by scoring 25 , while two other subjects $(9.5 \%)$ showed low self-esteem by scoring between 10 and 24 .

When the Rosenberg scale was related to the Jackson PRF-E, there was a direct relationship ( $r=$ $0.52, p<0.05$ ) between self-esteem and need for desirability (Jackson scale title: Desirability). Therefore, those subjects with the greatest need for desirability reported the highest self-esteem. A direct relationship was also found between self-esteem and need for order (Order, $r=0.50, p<0.05$ ), such that those with the higher self-esteem had the greater need for order. On the other hand, there was an inverse relationship between self-esteem and harm avoidance $(r=-0.51, p<0.05)$, such that those with the highest self-esteem displayed the least harm avoidance. However, no relationship was found between self-esteem and adult IQ scores no between self-esteem and the subjects' New York Heart Association Functional Classifications.

\section{Questionnaire-Interview}

The questionnaire-interview provided educational and socioeconomic information on the 21 subjects. The highest level of educational achievement included four subjects $(19.0 \%)$ with a postsecondary degree, $15(71.4 \%)$ with a high-school diploma, and two $(9.5 \%)$ who did not complete high school. Of the two subjects without high-school diplomas, one was mentally retarded and one was permanently disabled. Among the entire group, the disabled individual was the only subject who had exhibited severe cyanosis prior to surgical repair in childhood.

In their present adult lives, 11 subjects $(52.4 \%)$ had career jobs at the white-collar, managerial, executive, or professional levels. Eight subjects $(38.1 \%)$ worked at either skilled or unskilled bluecollar jobs and two subjects $(9.5 \%)$ did not work. These job levels translated into four subjects (19.0\%) earning individual incomes $>\$ 20,000$ annually, seven subjects $(33.3 \%)$ earning $\$ 10,000-$ $\$ 20,000$, and ten subjects $(47.6 \%)$ earning $<\$ 10,000$.

The fact that ten of the 21 subjects earned $<\$ 10,000$ is predominantly a reflection of sex differences. Only two men were among this group, and they were either mentally retarded or permanently disabled. The eight women earning $<\$ 10,000$ included six who were not the primary wage earners in their families, one who was an unwed mother, and one who was unemployed.

Overall, the educational and occupational information obtained from the questionnaire-interview was about what one would expect from this group of subjects, given their intellectual ability. This expectation was validated by direct relationships between the subjects' full-scale adult IQ scores and their educational degrees $(r=0.60, p<0.001)$, job levels $(r=0.54, p<0.003)$, and individual incomes $(r=0.55, p<0.002)$. Univariate one-way ANOVAs corroborated these relationships, indicating that those subjects with the higher full-scale adult IQs had the higher incomes, the higher job levels, and the higher educational degrees.

Furthermore, if the childhood TOF had affected adversely the subject's adult educational and occupational status, then one would expect to find that 
the subject's status was significantly lower than his same-sex sibling(s) and parent. However, statistical analysis using the chi-square goodness-of-fit technique indicated that the subjects did not have decreased status. On the contrary, the subjects had educational and occupational accomplishments similar to those of their same-sex parents and siblings. Compared with their same-sex parents, 11 subjects $(52.4 \%)$ had the same educational degree, seven $(33.3 \%)$ had a higher degree, and three $(14.3 \%)$ had a lower degree. Among the same-sex siblings, $18(60.0 \%)$ attained the same educational degree as the subjects, five $(16.7 \%)$ attained a higher degree, and seven (23.3\%) attained a lower degree.

\section{Discussion}

Linde et al. [9] have observed that surgical correction of the cardiac lesion in congenital heart disease was associated with improvement in intellectual functioning on psychological testing 3-6 months postoperatively, particularly in cyanotic children. No study prior to ours however, has provided a longitudinal assessment of intellectual functioning across two decades in patients with repaired congenital heart disease. While it is impossible to know what a person's IQ might have been in the absence of congenital heart disease, we found considerable stability between the preoperative child IQ and the postoperative adult IQ tested some 22 years apart in subjects with repaired TOF.

In conformity with the findings of two earlier studies [6, 19], our data indicated that repaired TOF does not impede a person from attaining his family's educational and occupational status. In spite of this favorable vocational outlook, however, one cannot infer that individuals with repaired TOF are unscathed by their disease. In an evaluation of young men aged 23-27 years, Ferencz [3] reported that pediatric cardiac patients were affected adversely not only by the medical complications of their disease, but also by a lack of social adjustment. Furthermore, Garson et al. [5] noted that patients with a mean age of 19.1 years who had undergone sur. gery for TOF an average of 6.5 years earlier scored significantly more in the neurotic range than expected by chance on the Cattell 16 PF personality inventory. We did not employ a direct measure of neurotic tendencies, but, in contrast to Garson, we did find that our group of subjects scored within the normal range on 17 of 22 Jackson personality scales. On five characteristics, they did score significantly higher (harm avoidance and giving nurturance) or lower (leadership, intellectual curiosity, and adaptability to change) than the normal range. Although, on an individual basis, direct relationships to childhood personality are difficult to discern, the adult group picture seems to fit a history of severe childhood illness and stress, low average intellectual development, and anxiety and dependency.

In comparing the Jackson personality scales to the subjects' current clinical status, we observed an inverse relationship between harm avoidance and the New York Heart Association Functional Classifications. Although this finding was not intuitive, it was consistent with Manning's [10] observation that problems of psychological maladjustment in congenital heart disease tend to be related inversely to the severity of the physical handicap.

An additional unanticipated finding was the high self-esteem reported by 17 of 21 subjects on the Rosenberg scale. Based on epidemiological data on the consequences of chronic illness [14], we would have anticipated that our subjects would exhibit low self-esteem. The explanation for the finding may lie in the design of this self-esteem test. The format of the Rosenberg scale has been criticized for producing only gross, ordinal distinctions among people [12]. While the scale has high reliability in measuring the self-acceptance aspect of self-esteem [15], the direct relationship that we found between reported self-esteem and need for desirability in our subjects also may have contributed to raise their scores higher than expected.

Overall, we recognize some limitations to our study. First, there is an absence of a control group of children with TOF who did not undergo surgery. On the other hand, we were able to draw direct comparisons between the subjects and their parents and siblings. Second, $15(71.4 \%)$ of the 21 subjects had one or more palliative procedures performed prior to the surgical repair for TOF. However, it is beyond the scope of our study to isolate the immediate and long-term effects of these palliative procedures on psychological and intellectual functioning from the effects of the cardiac repair. Third, we could not consider the minor numerical changes that some children exhibited in their IQ scores from one perioperative testing session to another, because not all of the children had participated in multiple batteries of testing. Therefore, our study was limited to the childhood data closest to, and usually immediately preceding, the surgical repair. Fourth, our subjects underwent surgical repair during the 1950 s and $1960 \mathrm{~s}$, when only the most promising TOF patients were chosen for surgical repair. The sickest TOF patients generally died or received just palliative procedures. Furthermore, surgery for repair of TOF was performed in children at an older age. In spite of these limitations, our findings have 
important implications for the large number of TOF patients who undergo surgical repair in childhood.

While the average age at surgical repair for our group of subjects was $8.7 \pm 3.9$ years, most current TOF patients undergo surgical repair prior to 4 years of age [13] or even in infancy [8]. The age at surgical repair may have a significant influence on the child's psychological development. Newburger et al. [11] found a significant inverse relationship between the age at which corrective surgery was performed and the cognitive functioning in children with a cyanotic congenital heart disease (transposition of the great arteries).

\section{Summary}

The subject's intelligence scores were related directly to their educational degrees, job levels, and individual incomes. Comparing adult IQs with child IQs, we found high stability across $22.3 \pm 2.2$ years. On the Jackson personality scales, the subjects scored high on harm avoidance and giving nurturance to others. They scored low on intellectual curiosity, leadership skills, and adaptability to change. The childhood group personality profile was compatible with the adult group personality traits. Despite some personality characteristics reflective of their severe childhood illness, the subjects' adult psychosocial status appears consistent with their intellectual level and family background. Therefore, we conclude that the results of perioperative psychological testing in children with TOF are congruent with postoperative adult intellectual and psychosocial status.

Acknowledgments. We wish to acknowledge and thank Cher Szpunar for the computer statistical analysis, and to express our appreciation to Aaron Stern, MD, and Ralph Gibson, PhD, who initiated these studies with the children. This work was supported in part by the Clinical Research Center Program of the University of Michigan Hospitals, grant MO IRR00042 from the National Institutes of Health.

\section{References}

1. Blalock A, Taussig HB (1945) The surgical treatment of malformations of the heart in which there is pulmonary stenosis or pulmonary atresia. $J A M A \quad I 28 ; 189-202$
2. Criteria Committee of the New York Heart Association (1964) Nomenclature and criteria for diagnosis of diseases of the heart and great vessels, 6th edn. Little, Brown, Boston

3. Ferencz C (1974) The quality of life of the adolescent cardiac patient. Postgrad Med 56:67-73

4. Fyler D (1980) Report of the New England Regional Infant Cardiac Program. Pediatrics [Suppl]65:375-461

5. Garson A, Williams RB, Reckless J (1974) Long-term follow-up of patients with tetralogy of Fallot: physical health and psychopathology. J Pediatr 85:429-433

6. Gersony WM, Malm JR (1973) Late results of repair of tetralogy of Fallot. In: Kirklin JW (ed) Advances in cardiovascular surgery. Grune and Stratton. New York, pp 17-27

7. Jackson DN (1974) Personality research form manual. Research Psychologists Press, Goshen NY

8. Kirklin JW, Barratt-Boyes BG (1986) Cardiac surgery: morphology, diagnostic criteria, natural history, techniques, results, and indications. John Wiley, New York, pp 765-766

9. Linde LM, Rasof B, Dunn OJ (1970) Longitudinal studies of intellectual and behavioral development in children with congenital heart disease. Acta Paediatr Scand 59:169-176

10. Manning JA (1983) Congenital heart disease and the quality of life. In: Engle MA, Perloff JK (eds) Congenital heart disease after surgery: benefits, residua, sequelae. Yorke Medical Books, New York, pp 347-361

11. Newburger JW, Silbert AR, Buckley LP, Fyler DC (1984) Cognitive function and age at repair of transposition of the greal arteries in children. $N$ Engl $J$ Med 310:1495-1499

12. Nunnally J (1967) Psychometric theory. McGraw-Hill, New York

13. Pacifico AD, Bargeron LM, Kirklin JW (1973) Primary total correction of tetralogy of Fallot in children less than 4 years of age. Circulation 48:1085-1091

14. Pless IB, Roghmann KJ (1971) Chronic illness and its consequences: observations based on three epidemiologic surveys. J Pediatr 79:351-359

15. Robinson JP, Shaver PR (1973) Measures of social psychological attirudes. Institute for Social Research, Ann Arbor MI

16. Rosenberg M (1965) Society and the adolescent self-image. Princeton University Press, Princeton NJ

17. Rosenthal A, Behrendt D, Sloan H, Ferguson P, Snedecor S, Schork MA (1984) Long term prognosis (15-26 years) after repair to tetralogy of Fallot. I. Survival and symptomatic status. Ann Thorac Surg 38:151-156

18. Silbert A, Wolff PH, Mayer B, Rosenthal A, Nadas AS (1969) Cyanotic heart disease and psychological development. Pediatrics 43:192-200

19. Taussig HB, Kallman CH, Nagal, D, Baumgardner R, Momberger $\mathrm{N}$, Kirk $\mathrm{H}$ (1975) Long-time observations in the Blalock-Taussig operation. VIII. 20-28 year follow-up on patients with tetralogy of Fallot. Johns Hopkins Med $J$ 137:13-19

20. Wechsler D (1981) WAIS-R manual. Psychological Corp, New York 